\title{
Iteration for a Third-Order Three-Point BVP with Sign-Changing Green's Function
}

\author{
Ya-Hong Zhao and Xing-Long Li \\ Department of Applied Mathematics, Lanzhou University of Technology, Lanzhou, Gansu 730050, China \\ Correspondence should be addressed to Ya-Hong Zhao; yhzhao0931@163.com
}

Received 23 January 2014; Accepted 1 February 2014; Published 19 March 2014

Academic Editor: Fazlollah Soleymani

Copyright ( 2014 Y.-H. Zhao and X.-L. Li. This is an open access article distributed under the Creative Commons Attribution License, which permits unrestricted use, distribution, and reproduction in any medium, provided the original work is properly cited.

We are concerned with the following third-order three-point boundary value problem: $u^{\prime \prime \prime}(t)=f(t, u(t)), t \in[0,1], u l(0)=u(1)=$ $0, u^{\prime \prime}(\eta)+\alpha u(0)=0$, where $\alpha \in[0,2)$ and $\eta \in[2 / 3,1)$. Although corresponding Green's function is sign-changing, we still obtain the existence of monotone positive solution under some suitable conditions on $f$ by applying iterative method. An example is also included to illustrate the main results obtained.

\section{Introduction}

Third-order differential equations arise from a variety of different areas of applied mathematics and physics, for example, in the deflection of a curved beam having a constant or varying cross-section, a three-layer beam, electromagnetic waves or gravity driven flows, and so on [1].

Recently, the existence of single or multiple positive solutions to some third-order three-point boundary value problems (BVPs) has received much attention from many authors; see [2-7] and the references therein. However, all the above-mentioned papers are achieved when corresponding Green's functions are nonnegative, which is a very important condition. A natural question is that whether we can obtain the existence of positive solutions to some third-order threepoint BVPs when corresponding Green's functions are signchanging.

In 2008, Palamides and Smyrlis [8] studied the existence of at least one positive solution to the singular third-order three-point BVP with an indefinitely signed Green's function

$$
\begin{gathered}
u^{\prime \prime \prime}(t)=a(t) f(t, u(t)), \quad t \in(0,1), \\
u(0)=u(1)=u^{\prime \prime}(\eta)=0,
\end{gathered}
$$

where $\eta \in(17 / 24,1)$. Their technique was a combination of the Guo-Krasnoselskii fixed point theorem $[9,10]$ and properties of the corresponding vector field.
Very recently, for the third-order three-point BVP with sign-changing Green's function

$$
\begin{gathered}
u^{\prime \prime \prime}(t)=f(t, u(t)), \quad t \in[0,1], \\
u^{\prime}(0)=u(1)=u^{\prime \prime}(\eta)=0,
\end{gathered}
$$

Sun and Zhao proved the existence of single or multiple positive solutions when $\eta \in(1 / 2,1)$ by using the GuoKrasnoselskii and Leggett-Williams fixed point theorems in $[11,12]$ and obtained the existence of a positive solution when $\eta \in[2-\sqrt{2}, 1)$ by using iterative technique in [13].

In 2013, Li et al. [14] established the existence of at least one positive solution to the following third-order three-point BVP with sign-changing Green's function:

$$
\begin{gathered}
u^{\prime \prime \prime}(t)=f(t, u(t)), \quad t \in[0,1], \\
u^{\prime}(0)=u(1)=0, \quad u^{\prime \prime}(\eta)+\alpha u(0)=0,
\end{gathered}
$$

where $\alpha \in[0,2)$ and $\eta \in[(\sqrt{121+24 \alpha}-5) / 3(4+\alpha), 1)$. The main tool used was the Guo-Krasnoselskii fixed point theorem $[9,10]$.

It is worth mentioning that there are other types of works on sign-changing Green's functions which prove the existence of sign-changing solutions, positive in some cases; see Infante and Webb's papers [15-17]. 
Motivated greatly by the above-mentioned works, in this paper, we will study the BVP (3) by applying iterative method. Throughout this paper, we always assume that $\alpha \epsilon$ $[0,2)$ and $\eta \in[2 / 3,1)$. Although corresponding Green's function is sign-changing, we still obtain the existence of monotone positive solution for the BVP (3) under some suitable conditions on $f$. Moreover, our iterative scheme starts off with zero function, which implies that the iterative scheme is feasible.

\section{Main Results}

For any $y \in C[0,1]$, we consider the BVP

$$
\begin{gathered}
u^{\prime \prime \prime}(t)=y(t), \quad t \in[0,1], \\
u^{\prime}(0)=u(1)=0, \quad u^{\prime \prime}(\eta)+\alpha u(0)=0 .
\end{gathered}
$$

It follows from [14] that the expression of Green's function $G(t, s)$ of the BVP $(4)$ is as follows:

$$
G(t, s)=g_{1}(t, s)+g_{2}(t, s)+g_{3}(\eta, t, s),
$$

where

$$
\begin{aligned}
& g_{1}(t, s)=-\frac{\left(2-\alpha t^{2}\right)(1-s)^{2}}{2(2-\alpha)}, \quad(t, s) \in[0,1] \times[0,1], \\
& g_{2}(t, s)= \begin{cases}0, & 0 \leq t \leq s \leq 1, \\
\frac{(t-s)^{2}}{2}, & 0 \leq s \leq t \leq 1,\end{cases} \\
& g_{3}(\eta, t, s)= \begin{cases}0, & s \geq \eta \\
\frac{1-t^{2}}{2-\alpha}, & s<\eta\end{cases}
\end{aligned}
$$

and the $G(t, s)$ has the following properties:

$$
G(t, s) \geq 0 \quad \text { for } 0 \leq s<\eta, \quad G(t, s) \leq 0 \quad \text { for } \eta \leq s \leq 1 .
$$

Moreover, for $s \geq \eta$,

$$
\begin{gathered}
\max \{G(t, s): t \in[0,1]\}=G(1, s)=0 \\
\min \{G(t, s): t \in[0,1]\}=G(0, s)=-\frac{(1-s)^{2}}{2-\alpha} \geq-\frac{(1-\eta)^{2}}{2-\alpha},
\end{gathered}
$$

and, for $s<\eta$,

$$
\begin{gathered}
\max \{G(t, s): t \in[0,1]\}=G(0, s)=\frac{2 s-s^{2}}{2-\alpha} \leq \frac{2 \eta-\eta^{2}}{2-\alpha}, \\
\min \{G(t, s): t \in[0,1]\}=G(1, s)=0 .
\end{gathered}
$$

So, if we let $M=\max \{|G(t, s)|: t, s \in[0,1]\}$, then

$$
M=\max \left\{\frac{(1-\eta)^{2}}{2-\alpha}, \frac{2 \eta-\eta^{2}}{2-\alpha}\right\}<\frac{1}{2-\alpha} .
$$

Let Banach space $E=C[0,1]$ be equipped with the norm $\|u\|=\max _{t \in[0,1]}|u(t)|$ and

$$
K=\{y \in E: y(t)
$$

is nonnegative and decreasing on $[0,1]\}$.

Then $K$ is a cone in $E$. Note that this induces an order relation “ $\lesssim$ " in $E$ by defining $u \lesssim v$ if and only if $v-u \in K$.

In the remainder of this paper, we always assume that $f \in$ $C([0,1] \times[0,+\infty),[0,+\infty))$ and satisfies the following two conditions:

$\left(H_{1}\right)$ for each $u \in[0,+\infty)$, the mapping $t \mapsto f(t, u)$ is decreasing;

$\left(H_{2}\right)$ for each $t \in[0,1]$, the mapping $u \mapsto f(t, u)$ is increasing.

Now, we define an operator $T$ as follows:

$$
(T u)(t)=\int_{0}^{1} G(t, s) f(s, u(s)) d s, \quad u \in K, t \in[0,1] .
$$

Obviously, if $u$ is a fixed point of $T$ in $K$, then $u$ is a nonnegative and decreasing solution of the BVP (3).

Lemma 1. $T: K \rightarrow K$ is completely continuous.

Proof. Let $u \in K$. Then, for $t \in[0, \eta]$, we have

$$
\begin{aligned}
(T u)(t)= & \int_{0}^{t}\left[g_{1}(t, s)+\frac{(t-s)^{2}}{2}+\frac{1-t^{2}}{2-\alpha}\right] f(s, u(s)) d s \\
& +\int_{t}^{\eta}\left[g_{1}(t, s)+\frac{1-t^{2}}{2-\alpha}\right] f(s, u(s)) d s \\
& +\int_{\eta}^{1} g_{1}(t, s) f(s, u(s)) d s
\end{aligned}
$$

which together with $\left(H_{1}\right)$ and $\left(H_{2}\right)$ implies that

$$
\begin{aligned}
(T u)^{\prime}(t)= & \frac{\alpha t}{2-\alpha} \int_{0}^{\eta}\left(s^{2}-2 s\right) f(s, u(s)) d s \\
& -\int_{0}^{t} s f(s, u(s)) d s-t \int_{t}^{\eta} f(s, u(s)) d s \\
& +\frac{\alpha t}{2-\alpha} \int_{\eta}^{1}(1-s)^{2} f(s, u(s)) d s \\
\leq & f(\eta, u(\eta))\left[\frac{\alpha t}{2-\alpha} \int_{0}^{\eta}\left(s^{2}-2 s\right) d s-\int_{0}^{t} s d s\right. \\
& \left.\left.-t \int_{t}^{\eta} d s+\frac{\alpha t}{2-\alpha}\right]_{\eta}^{1}(1-s)^{2} d s\right] \\
= & t f(\eta, u(\eta))\left[\frac{\alpha(1-3 \eta)}{3(2-\alpha)}-\eta+\frac{t}{2}\right] \\
\leq & t f(\eta, u(\eta))\left[\frac{\alpha(1-3 \eta)}{3(2-\alpha)}-\frac{\eta}{2}\right] \leq 0 .
\end{aligned}
$$


For $t \in[\eta, 1]$, we have

$$
\begin{aligned}
(T u)(t)= & \int_{0}^{\eta}\left[g_{1}(t, s)+\frac{(t-s)^{2}}{2}+\frac{1-t^{2}}{2-\alpha}\right] f(s, u(s)) d s \\
& +\int_{\eta}^{t}\left[g_{1}(t, s)+\frac{(t-s)^{2}}{2}\right] f(s, u(s)) d s \\
& +\int_{t}^{1} g_{1}(t, s) f(s, u(s)) d s,
\end{aligned}
$$

which together with $\left(H_{1}\right)$ and $\left(H_{2}\right)$ shows that

$$
\begin{aligned}
(T u)^{\prime}(t)= & \frac{\alpha t}{2-\alpha} \int_{0}^{\eta}\left(s^{2}-2 s\right) f(s, u(s)) d s \\
& +\int_{\eta}^{t}(t-s) f(s, u(s)) d s-\int_{0}^{\eta} s f(s, u(s)) d s \\
& +\frac{\alpha t}{2-\alpha} \int_{\eta}^{1}(1-s)^{2} f(s, u(s)) d s \\
\leq & f(\eta, u(\eta))\left[\frac{\alpha t}{2-\alpha} \int_{0}^{\eta}\left(s^{2}-2 s\right) d s+\int_{\eta}^{t}(t-s) d s\right. \\
& \left.-\int_{0}^{\eta} s d s+\frac{\alpha t}{2-\alpha} \int_{\eta}^{1}(1-s)^{2} d s\right] \\
= & t f(\eta, u(\eta))\left[\frac{\alpha(1-3 \eta)}{3(2-\alpha)}+\frac{t-2 \eta}{2}\right] \\
\leq & t f(\eta, u(\eta))\left[\frac{\alpha(1-3 \eta)}{3(2-\alpha)}+\frac{1-2 \eta}{2}\right] \leq 0 .
\end{aligned}
$$

So, $(T u)(t)$ is decreasing on $[0,1]$. At the same time, since $(T u)(1)=0$, we know that $(T u)(t)$ is nonnegative on $[0,1]$. This indicates that $T u \in K$. Furthermore, although $G(t, s)$ is not continuous, it follows from known textbook results, for example, see [18], that $T: K \rightarrow K$ is completely continuous.

Theorem 2. Assume that $f(t, 0) \not \equiv 0$ for $t \in[0,1]$ and there exist two positive constants $a$ and $b$ such that the following conditions are satisfied:

$\left(H_{3}\right) f(0, a) \leq(2-\alpha) a ;$

$\left(H_{4}\right) b\left(u_{2}-u_{1}\right) \leq f\left(t, u_{2}\right)-f\left(t, u_{1}\right) \leq 2 b\left(u_{2}-u_{1}\right), 0 \leq t \leq 1$, $0 \leq u_{1} \leq u_{2} \leq a$.

If we construct an iterative sequence $v_{n+1}=T v_{n}, n=$ $0,1,2, \ldots$, where $v_{0}(t) \equiv 0$ for $t \in[0,1]$, then $\left\{v_{n}\right\}_{n=1}^{\infty}$ converges to $v^{*}$ in $E$ and $v^{*}$ is a decreasing and positive solution of the $B V P(3)$.

Proof. Let $K_{a}=\{u \in K:\|u\| \leq a\}$. Then we may assert that $T: K_{a} \rightarrow K_{a}$.

In fact, if $u \in K_{a}$, then it follows from $\left(\mathrm{H}_{3}\right)$ that

$$
\begin{aligned}
0 \leq(T u)(t) & =\int_{0}^{1} G(t, s) f(s, u(s)) d s \\
& \leq \int_{0}^{1}|G(t, s)| f(0, a) d s \\
& \leq(2-\alpha) a M<a, \quad t \in[0,1],
\end{aligned}
$$

which shows that $\|T u\| \leq a$. So, $T: K_{a} \rightarrow K_{a}$.
Now, we prove that $\left\{v_{n}\right\}_{n=1}^{\infty}$ converges to $v^{*}$ in $E$ and $v^{*}$ is a decreasing and positive solution of the BVP (3).

Indeed, in view of $v_{0} \in K_{a}$ and $T: K_{a} \rightarrow K_{a}$, we have $v_{n} \in K_{a}, n=1,2, \ldots$. Since the set $\left\{v_{n}\right\}_{n=0}^{\infty}$ is bounded and $T$ is completely continuous, we know that the set $\left\{v_{n}\right\}_{n=1}^{\infty}$ is relatively compact. In what follows, we prove that $\left\{v_{n}\right\}_{n=0}^{\infty}$ is monotone by induction. First, it is obvious that $v_{1}-v_{0}=v_{1} \epsilon$ $K$, which shows that $v_{0} \lesssim v_{1}$. Next, we assume that $v_{k-1} \lesssim v_{k}$. Then $v_{k}-v_{k-1}$ is decreasing and $0 \leq v_{k-1}(t) \leq v_{k}(t) \leq a$, $t \in[0,1]$. So, it follows from $\left(H_{4}\right)$ that

$$
\begin{aligned}
& v_{k+1}^{\prime}(t)-v_{k}^{\prime}(t) \\
& =\frac{\alpha t}{2-\alpha} \int_{0}^{\eta}\left(s^{2}-2 s\right)\left[f\left(s, v_{k}(s)\right)-f\left(s, v_{k-1}(s)\right)\right] d s \\
& -\int_{0}^{t} s\left[f\left(s, v_{k}(s)\right)-f\left(s, v_{k-1}(s)\right)\right] d s \\
& -t \int_{t}^{\eta}\left[f\left(s, v_{k}(s)\right)-f\left(s, v_{k-1}(s)\right)\right] d s \\
& +\frac{\alpha t}{2-\alpha} \int_{\eta}^{1}(1-s)^{2}\left[f\left(s, v_{k}(s)\right)-f\left(s, v_{k-1}(s)\right)\right] d s \\
& \leq \frac{b \alpha t}{2-\alpha} \int_{0}^{\eta}\left(s^{2}-2 s\right)\left[v_{k}(s)-v_{k-1}(s)\right] d s \\
& -b \int_{0}^{t} s\left[v_{k}(s)-v_{k-1}(s)\right] d s \\
& -b t \int_{t}^{\eta}\left[v_{k}(s)-v_{k-1}(s)\right] d s \\
& +\frac{2 b \alpha t}{2-\alpha} \int_{\eta}^{1}(1-s)^{2}\left[v_{k}(s)-v_{k-1}(s)\right] d s \\
& \leq b\left[v_{k}(\eta)-v_{k-1}(\eta)\right] \\
& \times\left\{\frac{\alpha t}{2-\alpha} \int_{0}^{\eta}\left(s^{2}-2 s\right) d s\right. \\
& \left.-\int_{0}^{t} s d s-t \int_{t}^{\eta} d s+\frac{2 \alpha t}{2-\alpha} \int_{\eta}^{1}(1-s)^{2} d s\right\} \\
& =b\left[v_{k}(\eta)-v_{k-1}(\eta)\right] t \\
& \times\left[\frac{\alpha\left(-\eta^{3}+3 \eta^{2}-6 \eta+2\right)}{3(2-\alpha)}-\eta+\frac{t}{2}\right] \\
& \leq b\left[v_{k}(\eta)-v_{k-1}(\eta)\right] t\left[\frac{\alpha\left(-\eta^{3}+3 \eta^{2}-6 \eta+2\right)}{3(2-\alpha)}-\frac{\eta}{2}\right] \\
& \leq b\left[v_{k}(\eta)-v_{k-1}(\eta)\right] t\left[\frac{\alpha(-3 \eta+2)}{3(2-\alpha)}-\frac{\eta}{2}\right] \\
& \leq 0, \quad t \in[0, \eta], \\
& v_{k+1}^{\prime}(t)-v_{k}^{\prime}(t) \\
& =\frac{\alpha t}{2-\alpha} \int_{0}^{\eta}\left(s^{2}-2 s\right)\left[f\left(s, v_{k}(s)\right)-f\left(s, v_{k-1}(s)\right)\right] d s \\
& +\int_{\eta}^{t}(t-s)\left[f\left(s, v_{k}(s)\right)-f\left(s, v_{k-1}(s)\right)\right] d s \\
& -\int_{0}^{\eta} s\left[f\left(s, v_{k}(s)\right)-f\left(s, v_{k-1}(s)\right)\right] d s \\
& +\frac{\alpha t}{2-\alpha} \int_{\eta}^{1}(1-s)^{2}\left[f\left(s, v_{k}(s)\right)-f\left(s, v_{k-1}(s)\right)\right] d s
\end{aligned}
$$




$$
\begin{aligned}
\leq & \frac{b \alpha t}{2-\alpha} \int_{0}^{\eta}\left(s^{2}-2 s\right)\left[v_{k}(s)-v_{k-1}(s)\right] d s \\
& +2 b \int_{\eta}^{t}(t-s)\left[v_{k}(s)-v_{k-1}(s)\right] d s \\
& -b \int_{0}^{\eta} s\left[v_{k}(s)-v_{k-1}(s)\right] d s \\
& +\frac{2 b \alpha t}{2-\alpha} \int_{\eta}^{1}(1-s)^{2}\left[v_{k}(s)-v_{k-1}(s)\right] d s \\
\leq & b\left[v_{k}(\eta)-v_{k-1}(\eta)\right] \\
& \times\left[\frac{\alpha t}{2-\alpha} \int_{0}^{\eta}\left(s^{2}-2 s\right) d s+2 \int_{\eta}^{t}(t-s) d s\right. \\
= & b\left[v_{0}^{\eta}(\eta)-v_{k-1}(\eta)\right] \\
& \times\left[\frac{\alpha t\left(-\eta^{3}+3 \eta^{2}-6 \eta+2\right)}{3(2-\alpha)}+t^{2}-2 \eta t+\frac{\eta^{2}}{2}\right] \\
\leq & b\left[v_{k}(\eta)-v_{k-1}(\eta)\right] t \\
& \times\left[\frac{\alpha\left(-\eta^{3}+3 \eta^{2}-6 \eta+2\right)}{3(2-\alpha)}+t-\frac{3 \eta}{2}\right] \\
\leq & b\left[v_{k}(\eta)-v_{k-1}(\eta)\right] t\left[\frac{\alpha(-3 \eta+2)}{3(2-\alpha)}+\frac{2-3 \eta}{2}\right] \\
\leq & 0, \quad t \in[\eta, 1] .
\end{aligned}
$$

So,

$$
v_{k+1}^{\prime}(t)-v_{k}^{\prime}(t) \leq 0, \quad t \in[0,1] .
$$

This together with $v_{k+1}(1)-v_{k}(1)=\int_{0}^{1} G(1, s)\left[f\left(s, v_{k}(s)\right)-\right.$ $\left.f\left(s, v_{k-1}(s)\right)\right] d s=0$ implies that

$$
v_{k+1}(t)-v_{k}(t) \geq 0, \quad t \in[0,1] .
$$

In view of (19) and (20), we know that $v_{k+1}-v_{k} \in K$, which indicates that $v_{k} \lesssim v_{k+1}$. Thus, we have shown that $v_{n} \lesssim$ $v_{n+1}, n=0,1,2 \ldots$. Since $\left\{v_{n}\right\}_{n=1}^{\infty}$ is relatively compact and monotone, there exists $v^{*} \in K_{a}$ such that $\lim _{n \rightarrow \infty} v_{n}=v^{*}$, which together with the continuity of $T$ and the fact that $v_{n+1}=T v_{n}$ implies that $v^{*}=T v^{*}$. This indicates that $v^{*}$ is a decreasing and nonnegative solution of the BVP (3). Moreover, since $f(t, 0) \neq \equiv$ for $t \in[0,1]$, we know that zero function is not a solution of the BVP (3), which shows that $v^{*}$ is a positive solution of the BVP (3).

\section{An Example}

Consider the BVP

$$
\begin{gathered}
u^{\prime \prime \prime}(t)=\frac{1}{16} u^{2}(t)+\frac{1}{4} u(t)+(1-t), \quad t \in[0,1], \\
u^{\prime}(0)=u(1)=0, \quad u^{\prime \prime}(\eta)+u(0)=0 .
\end{gathered}
$$

If we let $\alpha=1, \eta=7 / 9$, and $f(t, u)=(1 / 16) u^{2}+$ $(1 / 4) u+(1-t),(t, u) \in[0,1] \times[0,+\infty)$, then all the hypotheses of Theorem 2 are fulfilled with $a=2$ and $b=1 / 4$. Therefore, it follows from Theorem 2 that the BVP (21) has a decreasing and positive solution. Moreover, the iterative scheme is $v_{0}(t) \equiv 0$ for $t \in[0,1]$ and

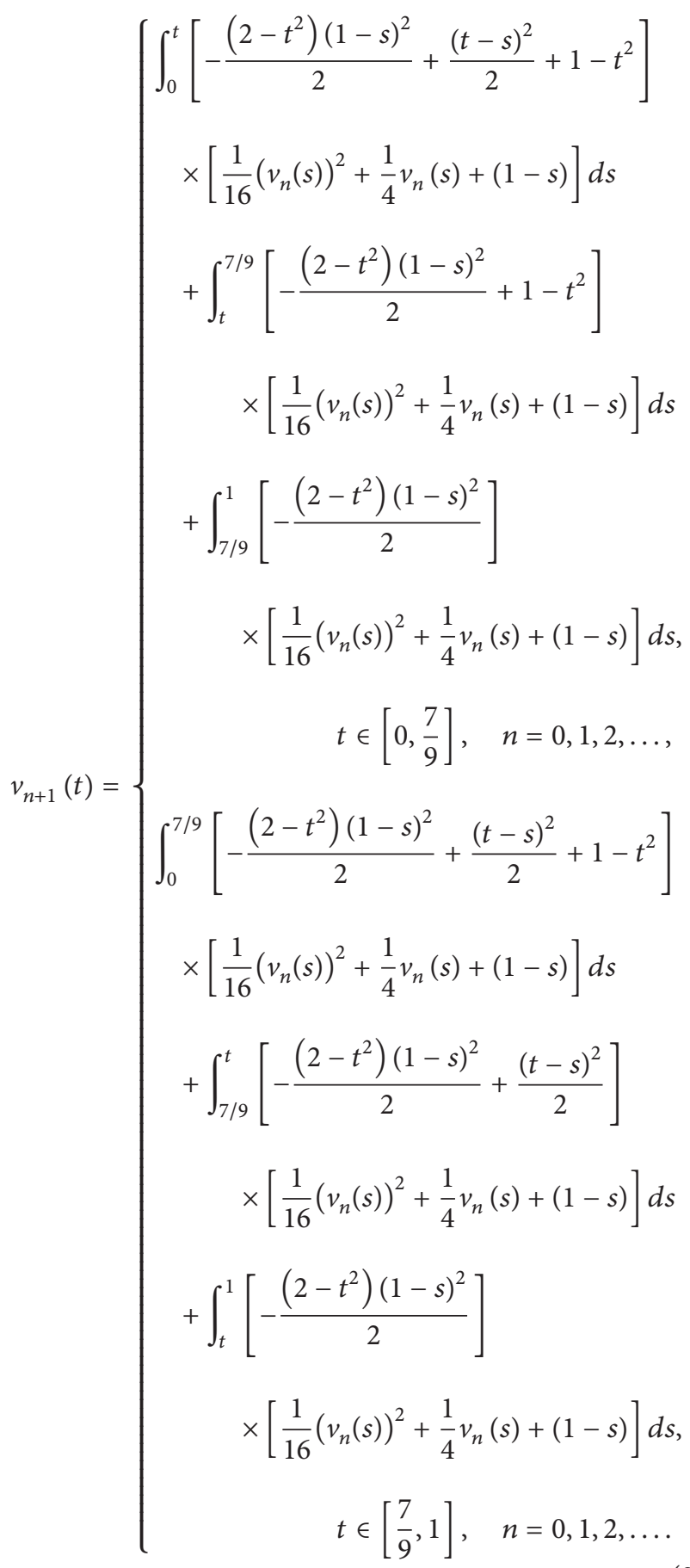

The first, second, third, and fourth terms of this scheme are as follows:

$$
v_{0}(t) \equiv 0,
$$$$
v_{1}(t)=-\frac{1}{24} t^{4}+\frac{1}{6} t^{3}-\frac{227}{648} t^{2}+\frac{73}{324},
$$ 


$$
\begin{aligned}
& v_{2}(t)=\frac{1}{55296} t^{11}-\frac{35}{165888} t^{10}+\frac{839}{746496} t^{9}-\frac{7489}{2239488} t^{8} \\
& +\frac{137893}{40310784} t^{7}+\frac{1415521}{120932352} t^{6}-\frac{481871}{10077696} t^{5} \\
& +\frac{162649}{10077696} t^{4}+\frac{1987201}{10077696} t^{3}-\frac{481465}{1119744} t^{2} \\
& +\frac{951409}{3779136} \\
& v_{3}(t)=\frac{1}{293534171136} t^{25}-\frac{1}{10871635968} t^{24} \\
& +\frac{9341}{7925422620672} t^{23}-\frac{24949}{2641807540224} t^{22} \\
& +\frac{1842703}{35664401793024} t^{21}-\frac{20695715}{106993205379072} t^{20} \\
& +\frac{1261406617}{2888816545234944} t^{19}-\frac{131313793}{962938848411648} t^{18} \\
& -\frac{463466345483}{155996093442686976} t^{17} \\
& +\frac{20201622953}{1925877696823296} t^{16} \\
& -\frac{4124079293903}{467988280328060928} t^{15} \\
& -\frac{213831233807699}{4211894522952548352} t^{14} \\
& +\frac{1890940354637}{9749755840167936} t^{13} \\
& -\frac{86168085379277}{526486815369068544} t^{12} \\
& -\frac{14488536542111}{19499511680335872} t^{11} \\
& +\frac{436989616007405}{175495605123022848} t^{10} \\
& -\frac{42359864609123}{29249267520503808} t^{9} \\
& -\frac{2156592823827731}{263243407684534272} t^{8} \\
& +\frac{186526068980179}{9749755840167936} t^{7} \\
& +\frac{413727883674101}{263243407684534272} t^{6} \\
& -\frac{13158305753867}{203119913336832} t^{5}+\frac{432683614811977}{10968475320188928} t^{4} \\
& +\frac{92539330261825}{457019805007872} t^{3}-\frac{1830285163670609}{4113178245070848} t^{2} \\
& +\frac{1148605916775291}{4503599627370496} \text {. }
\end{aligned}
$$

\section{Conclusion}

In [14], only the existence of at least one positive solution to the BVP (3) was obtained when $\alpha \in[0,2)$ and $\eta \in$ $[(\sqrt{121+24 \alpha}-5) / 3(4+\alpha), 1)$. In this paper, when $\alpha \in[0,2)$ and $\eta \in[2 / 3,1)$, we have successfully constructed an iterative sequence, whose limit is just a desired monotone positive solution of the BVP (3). Moreover, our iterative scheme starts off with zero function, which implies that the iterative scheme is feasible.

\section{Conflict of Interests}

The authors declare that there is no conflict of interests regarding the publication of this paper.

\section{References}

[1] M. Greguš, Third Order Linear Differential Equations, vol. 22, Reidel, Dordrecht, The Netherlands, 1987.

[2] D. R. Anderson, "Green's function for a third-order generalized right focal problem," Journal of Mathematical Analysis and Applications, vol. 288, no. 1, pp. 1-14, 2003.

[3] Z. Bai and X. Fei, "Existence of triple positive solutions for a third order generalized right focal problem," Mathematical Inequalities \& Applications, vol. 9, no. 3, pp. 437-444, 2006.

[4] L.-J. Guo, J.-P. Sun, and Y.-H. Zhao, "Existence of positive solutions for nonlinear third-order three-point boundary value problems," Nonlinear Analysis: Theory, Methods \& Applications, vol. 68, no. 10, pp. 3151-3158, 2008.

[5] A. P. Palamides and N. M. Stavrakakis, "Existence and uniqueness of a positive solution for a third-order three-point boundary-value problem," Electronic Journal of Differential Equations, vol. 2010, no. 155, pp. 1-12, 2010.

[6] Y. Sun, "Positive solutions of singular third-order three-point boundary value problem," Journal of Mathematical Analysis and Applications, vol. 306, no. 2, pp. 589-603, 2005.

[7] Q. Yao, "The existence and multiplicity of positive solutions for a third-order three-point boundary value problem," Acta Mathematicae Applicatae Sinica, vol. 19, no. 1, pp. 117-122, 2003.

[8] A. P. Palamides and G. Smyrlis, "Positive solutions to a singular third-order three-point boundary value problem with an indefinitely signed Green's function," Nonlinear Analysis: Theory, Methods \& Applications, vol. 68, no. 7, pp. 2104-2118, 2008.

[9] D. J. Guo and V. Lakshmikantham, Nonlinear Problems in Abstract Cones, vol. 5, Academic Press, New York, NY, USA, 1988.

[10] M. A. Krasnoselskii, Positive Solutions of Operator Equations, Noordhoff, Groningen, The Netherlands, 1964.

[11] J.-P. Sun and J. Zhao, "Positive solution for a third-order threepoint boundary value problem with sign-changing Green's function," Communications in Applied Analysis, vol. 16, no. 2, pp. 219-228, 2012.

[12] J.-P. Sun and J. Zhao, "Multiple positive solutions for a third-order three-point BVP with sign-changing Green's function," Electronic Journal of Differential Equations, vol. 2012, no. 118, pp. 1-7, 2012.

[13] J.-P. Sun and J. Zhao, "Iterative technique for a third-order three-point BVP with sign-changing Green's function," Electronic Journal of Differential Equations, vol. 2013, no. 215, pp. 1-9, 2013.

[14] X.-L. Li, J.-P. Sun, and F.-D. Kong, "Existence of positive solution for a third-order three-point BVP with sign-changing Green's function," Electronic Journal of Qualitative Theory of Differential Equations, vol. 2013, no. 30, pp. 1-11, 2013. 
[15] G. Infante and J. R. L. Webb, "Nonzero solutions of Hammerstein integral equations with discontinuous kernels," Journal of Mathematical Analysis and Applications, vol. 272, no. 1, pp. 3042, 2002.

[16] G. Infante and J. R. L. Webb, “Three-point boundary value problems with solutions that change sign," Journal of Integral Equations and Applications, vol. 15, no. 1, pp. 37-57, 2003.

[17] G. Infante and J. R. L. Webb, "Loss of positivity in a nonlinear scalar heat equation," Nonlinear Differential Equations and Applications, vol. 13, no. 2, pp. 249-261, 2006.

[18] R. H. Martin, Nonlinear Operators and Differential Equations in Banach Spaces, John Wiley \& Sons, New York, NY, USA, 1976. 


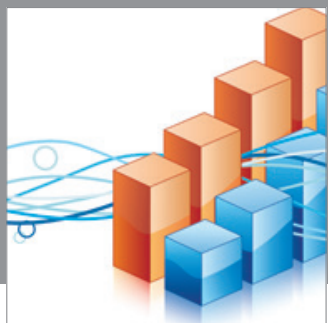

Advances in

Operations Research

mansans

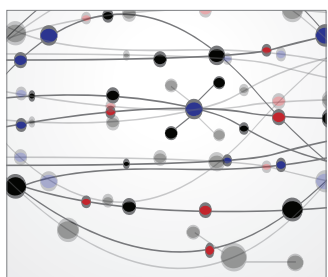

The Scientific World Journal
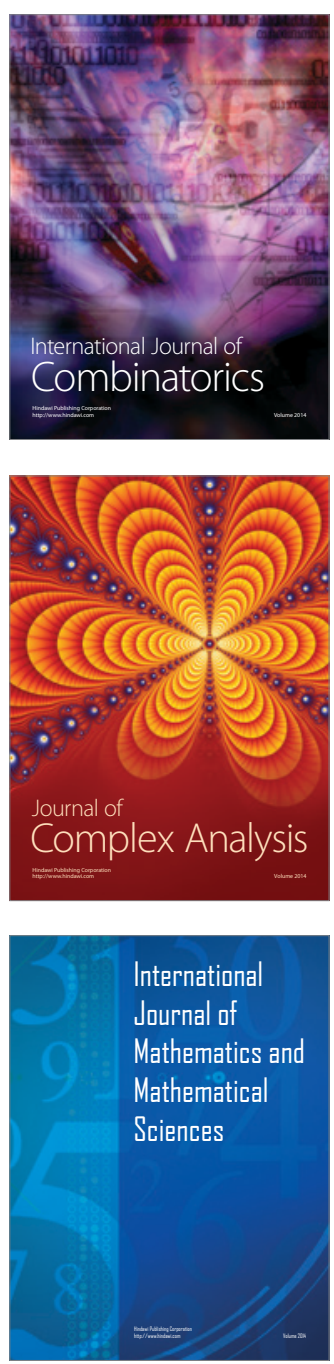
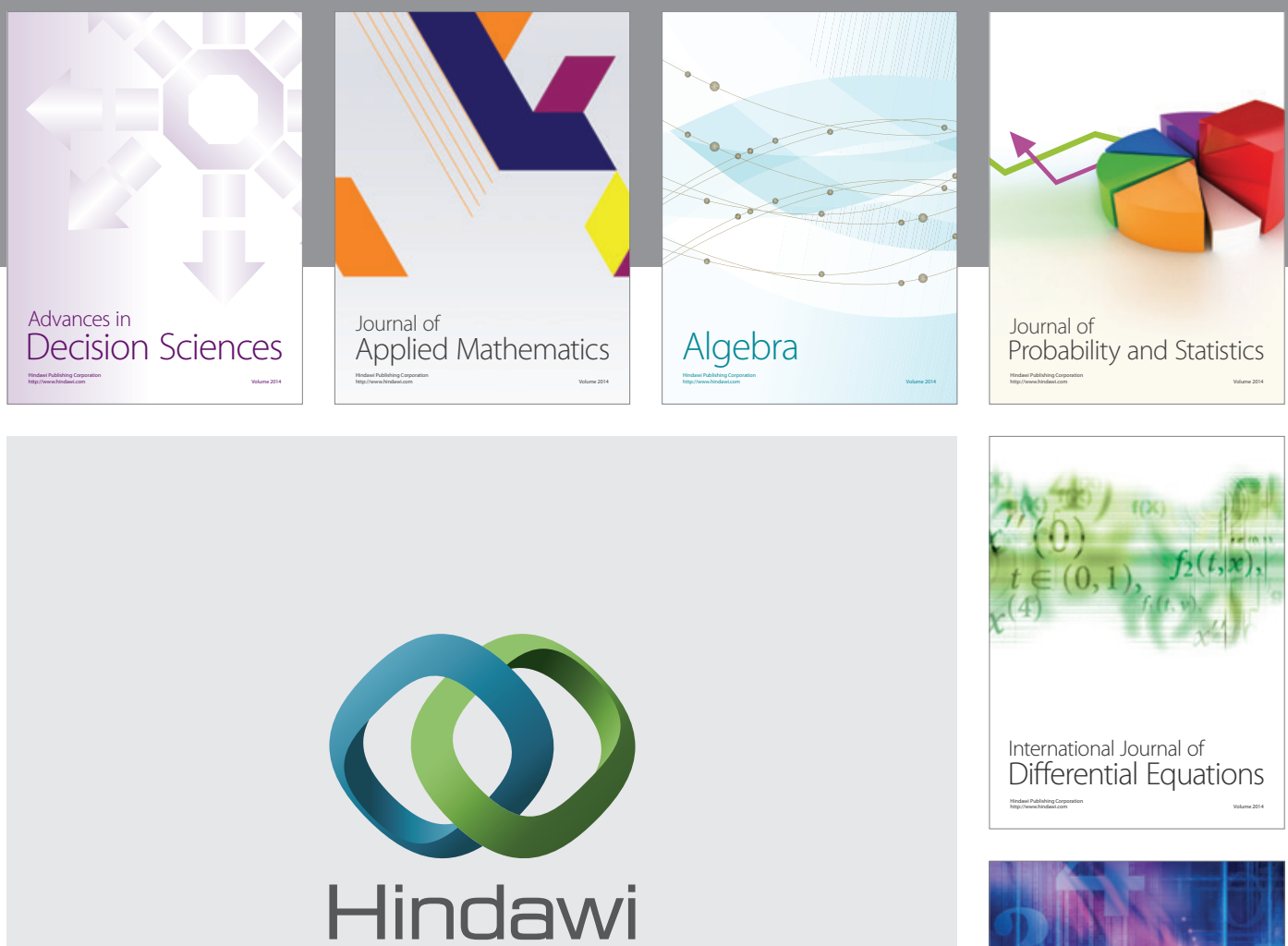

Submit your manuscripts at http://www.hindawi.com
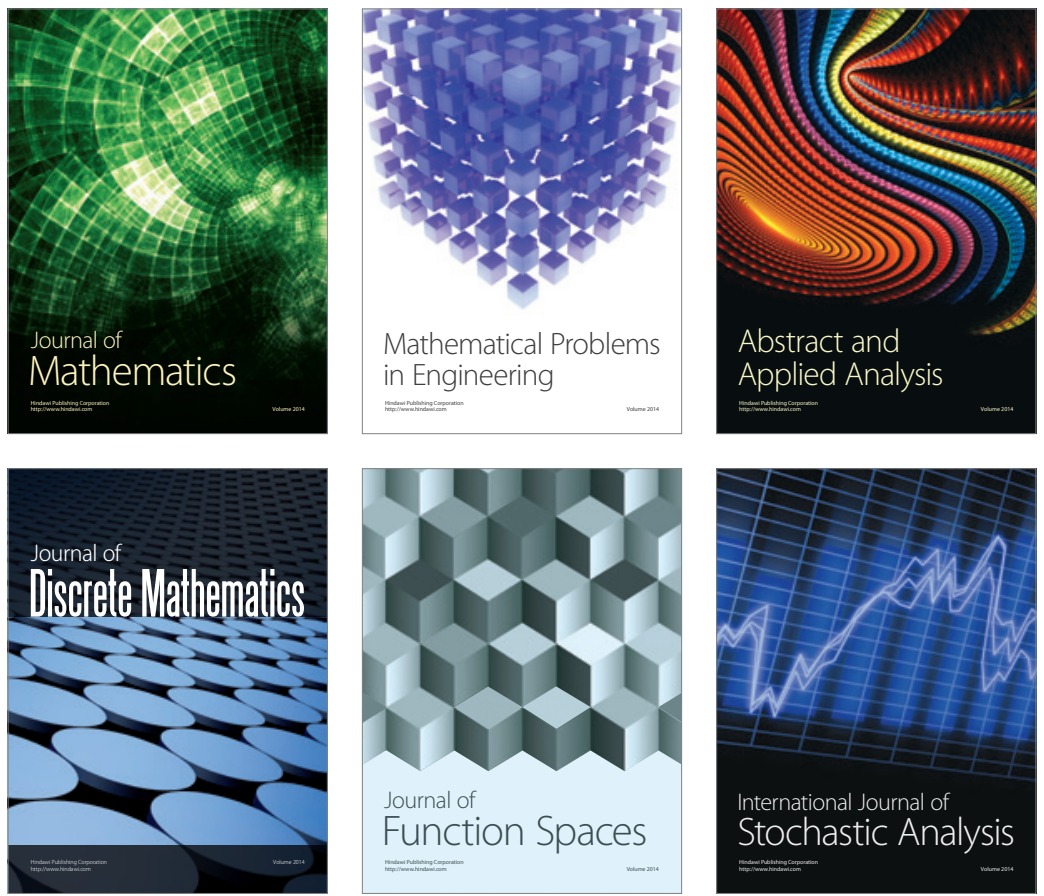

Journal of

Function Spaces

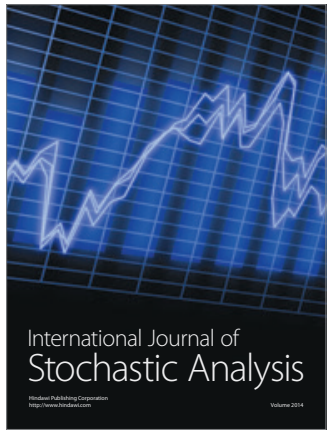

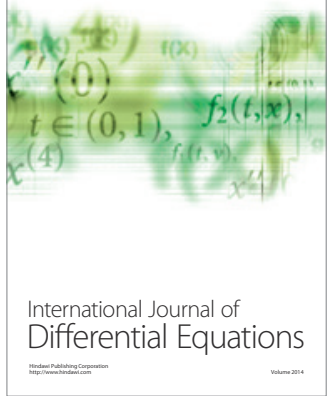
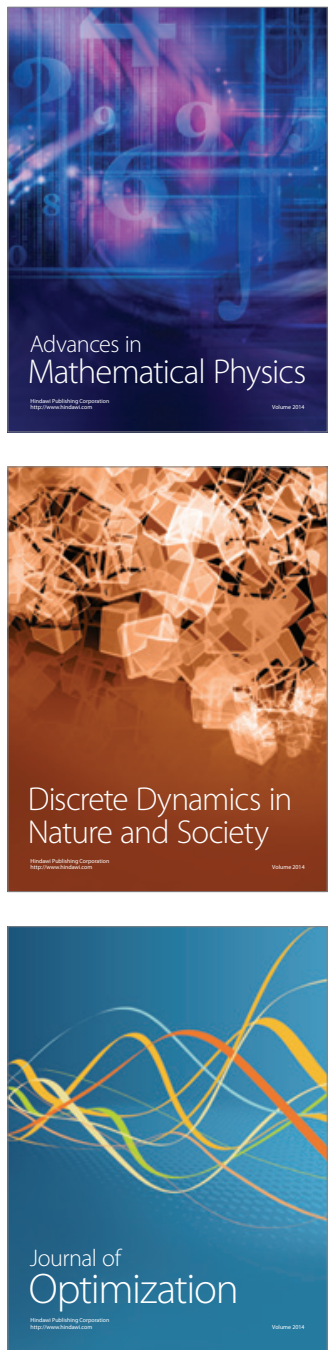